\title{
Overexpression of Medicago sativa glutamate-semialdehyde aminotransferase (GSA) gene in tobacco increased photosynthesis efficiency
}

\author{
Maryam Ghasemzadeh $^{1}$, Mahdi Khozeai ${ }^{2 *}{ }^{*}$ Hamzeh Amiri $^{1}$ \\ ${ }^{1}$ Department of Biology, University of Lorestan, Khorramabad, Iran \\ ${ }^{2}$ Department of Biology, University of Isfahan Iran \\ m.ghasemzadeh128@gmail.com \\ amiri_h_lu@yahoo.com \\ *Corresponding author: mkhoza@sci.ui.ac.ir \\ Tel: 00983132673139 \\ Date of submission: 15 may 2019.
}

Highlight

Overexpression of glutamate-semialdehyde aminotransferase (GSA) increase photosynthetic capacity, growth in tobacco.

\section{Abstract}

To investigate the effect of increased glutamate-semialdehyde aminotransferase (GSA) on photosynthetic capacity and growth, tobacco (Nicoliana tabacum L. Xanti) plants with increased levels of glutamate-semialdehyde aminotransferase protein were produced. This was achieved using a cassette composed of a full-length Medicago sative cDNA under the control of the cauliflower mosaic virus 35S promoter. The results revealed distinct impacts of GSA activity on photosynthesis rate and growth in GSA over expression tobacco plants. In transgenic plants with increased GSA activity, an increase in soluble and insoluble sugars accumulation was evident. Total biomass, leaf area, plant height and internode 3-4 were increased in GSA sense plants, compared with equivalent wild-type tobacco plants. Moreover, transgenic tobacco plants with increased GSA activity exhibit higher levels of 5-aminolevulinic acid (ALA) accumulation and increased in content of chlorophyll and carotenoids pigments. Collectively, our data suggest that higher level of GSA activity gives an advantage to photosynthesis, growth in tobacco plants. This work also provides a case study that an individual enzyme in the biosynthesis of chlorophyll pathway may serve as a useful target for genetic engineering to improve photosynthesis and growth in plants. 
Key words: 5-aminolevulinic acid (ALA), chlorophyll, glutamate-semialdehyde aminotransferase (GSA), growth rate, photosynthesis rate, soluble sugar

Abbreviations

5-aminolevulinic acid: ALA

Glutamate-semialdehyde aminotransferase: GSA

\section{Introduction}

5-Aminolevulinate compound is an important biosynthetic precursor of all tetrapyrrole compounds such as chlorophyll, heme, sirohem, cobalamin (vitamin B12), and phytochrom (Fig. 1)(Mochizuki et al., 2010). ALA has received wide attention as a new plant growth regulator (PGRs) and growth-promoter (Bindu and Vivekanandan, 1998), stimulator assimilation of nitrogen (Wei et al., 2012) and sulfur (Maruyama-Nakashita et al., 2010), and as a biodegradable herbicide or insecticide (Rebeiz et al., 1988a; Sasaki et al., 2002; Yang et al., 2011; Xu et al., 2015) in agricultural application. ALA also has medical applications for cancer photodynamic therapy, tumor diagnosis (Wachowska et al., 2011), antimicrobial drug (Banerjee et al., 2010) and improvement sleep (Perez et al., 2013) and other clinical uses. At low concentrations (30-100 mg $1^{-1}$ ), ALA increases the yield of agricultural products also can improve plant tolerance to various stresses (Wang et al., 2004, 2010; Sun et al., 2009; Han et al., 2014; Yang et al., 2014; An et al., 2016b,a; Wu et al., 2018) promoting antioxidant activity (Nishihara et al., 2003) but at high concentrations known as an environmental friendly and biodegradable herbicide or insecticide 55 (Jung et al., 2004).

Two different pathways of ALA biosynthesis in living organisms have been observed. One is the C4 route that known as Shemin pathway. In this pathway ALA is formed from the condensation of succinyl-CoA and glycine, catalyzed by ALA synthetase (ALA-S) in the mitochondria of animals, yeast, fungi or in some kind of bacterial species. Another is the C5 route that known as Beale pathway, in that route glutamate is used as the precursor to form ALA after three enzymatic reactions occurring in the stroma of plastids of higher plants and in bryophytes, cyanobacteria and 
many eubacteria. Glutamate respectively convert by glutamyl-tRNA synthetase (Glu-RS), glutamyl-tRNA hydrogenase (Glu-TR), and glutamate-1-semialdehyde aminotransferase (GSR) to ALA (Beale, 1990; Wettstein et al., 1995; lida et al., 2002). Two molecules of ALA are condensed to form the monopyrrole (porphobilinogen; PBG). four molecules of PBG are polymerized to form the cyclic tetrapyrrole uroporphyrinogen III (Urogen III). The pathway is branched at this step to form siroheme (cofactor of nitrite and sulfite reductases which function in nitrogen and sulfur assimilation). Protoporphyrin IX (Proto IX) is formed by further steps including decarboxylations and oxidation. Ferroclatase and chelatase insert $\mathrm{Fe}^{2+}$ or $\mathrm{Mg}^{2+}$ to Proto IX. Subsequent changes lead to heme or chlorophyll (Chl) or, respectively (Fig.1).

Chemical production of ALA is very expensive so some studies were down in micro-organisms to biological produce of ALA for medical or agriculture purposes and a few studies were focused on plants (Xie et al., 2003; Choi et al., 2008; Yu et al., 2015; Yang et al., 2016; Kang et al., 2017; Zhang and Ye, 2018).

Up to now, there are many studies shown that exogenous ALA in low concentrations can improve tolerance of plants in stress (Wang et al., 2004, 2010; Sun et al., 2009; Han et al., 2014; Yang et al., 2014; An et al., 2016b,a; Wu et al., 2018; Phour et al., 2018) and as a plant growth regulator (PGRs) are widely applied to improve photosynthesis, growth, development, productivity (Xu et al., 2011; An et al., 2016a,b; Ye et al., 2016; Anjum et al., 2016; Tang et al., 2017; Liu et al., 2018) and good appearance and quality of products (Fuli Xu et al., 2012) of plants under both normal and stressful conditions.

In 1997 the yeast Hem1 gene (encoding aminolevulinate synthase in C4 route) was transferred into tobacco, The Heml gene could be expressed in transgenic tobacco, so more endogenous ALA was biosynthesized (Zavgorodnyaya et al., 1997). Then, ALA-S gene of Bradyrhizobium japonicum was introduced into the genome of rice. All transgenic rice lines expressed $A L A-S$, so higher levels of endogenous ALA and tetrapyrrole compounds was achieved (Jung et al., 2004), But transgenic rice lines were grown only under low light condition which was due to the accumulation of protoporphyrin IX, an intermediate of ALA metabolism, in the transgenic rice and photodynamic damage of transgenic lines in high light condition (Jung et al., 2004, 2008). Plant height, tiller number and yield of transgenic rice decreased compared to WT rice (Kuk, 
2007). In contrast, overexpression of Heml gene from yeast (McCormac et al., 2001) in to Arabidopsis thaliana showed more growth than the WT plants under light condition of PPFD about $1000 \mu \mathrm{mol} \mathrm{m} \mathrm{m}^{-2} \mathrm{~s}^{-1}$ at noon without any photobleaching (Zhang et al., 2010). The same results also obtained in tobacco transgenic lines with over expression of yeast Heml genes, the transgenic plants with upregulation of Heml gene had higher photosynthetic capacity than wild type tobacco (Zhang et al., 2011). Down regulation of ALA showed growth retardation and leaves phenotype which was accompanied with chlorophyll variegation pattern in antisense transgenic tobacco plants (Höfgen et al., 1994). Genetic manipulation of chlorophyll biosynthesis pathway in Arabidopsis, tobacco, Brassica and other crop plants showed significant changes in the amount of chlorophyll and pigments, and effects on quenching of $\mathrm{O}_{2}$ and other reactive oxygen species leads to changes photosynthesis, plant productivity and grain yield in normal growth conditions as well as in a stressful environment (Papenbrock et al., 2000; Tanaka et al., 2001; Alawady and Grimm, 2005).

In this study, Medicago sativa GSA was introduced into the genome of tobacco to modulate GSA activity. The results clearly demonstrated that overexpression of GSA met our hypothesis regarding to increase photosynthesis rate or positive impact on growth analysis. To the best of our knowledge, this is the first report that genetic engineering of Medicago sativa GSA could improve growth and photosynthetic pigments in transgenic plants. This would open up a new way to have

\section{MATERIALS AND METHODS}

\section{Preparation Overexpression Plant}

In this research, the cDNA of the GSA gene in Medicago sative L. (accession No: HQ244440.1) (Ferradini et al., 2011) were amplified by PCR using RB pfu polymerase kite (RNA biotechnology, Co, Isfahan Iran) and the following primers; Forward: GGATCCAAAATGGCTGCTTCGGGTATT, Backward: GAGCTCTCAGATCTCCCTAAAGA. The PCR reactions were as follow: for $94{ }^{\circ} \mathrm{C}$ for $5 \mathrm{~min}$ hot start, 30 cycles of $94{ }^{\circ} \mathrm{C}$ for $30 \mathrm{sec}$ denature, $55{ }^{\circ} \mathrm{C}$ for $30 \mathrm{sec}$ annealing, $72{ }^{\circ} \mathrm{C}$ for $1.5 \mathrm{~min}$ extension, and $72{ }^{\circ} \mathrm{C}$ for $10 \mathrm{~min}$ final 
extension. pBI121 plant expression vector as a binary vector containing the cauliflower mosaic virus promoter $\mathrm{CaMV} 35 \mathrm{~S}$ and transcription terminator sequences (NOS) and $\beta$-glucuronidase gene and a kanamycin resistance gene (NPTII) as a selection marker were used. After the sequence integrity of amplified GSA was verified by sequencing, pBI121 and the fragments of $G S A$ was digested with Bam HI and Sac I, then the fragments of GSA were ligated into pBI121 by T4 DNA ligase. The transfer of the pBI121-GSA was confirmed by PCR colony, digestion and DNA sequencing. Then pBI121-GSA was introduced into Agrobacterium tumefaciens strain LBA4404 based on a freeze/thaw protocol (Green and Sambrook, 2012). Then this transformed Agrobacterium used for transformation of tobacco based on Leaf-disk protocol (Horsch et al., 1985). The seventeen primary transgenic Tobacco lines (T0 generation) were selected on kanamycin-containing MS medium (Murasnige and Skoog, 1962) then were rooted on kanamycin-containing medium, then transferred to soil and grown to maturity. In order to confirm the presence of the GSA gene in putative transgenic tobacco, analysis of total DNA-PCR, RT-PCR and real time PCR were performed. Based on these selections in the T0 generation, three GSAoverexpressing lines (T0-1, T0-3, and T0-4) were chosen for subsequent analysis. Analysis done in 8-10 leave stage of T0 generation tobacco. Leaf of this lines rapidly frozen in liquid nitrogen for analysis.

T0-1, T0-3, T0-4, and WT Tobacco plants were grown in a controlled-environment cabinet, were Irrigated by Hoagland (Hoagland and Arnon, 1950) (temperature $25 \pm 5{ }^{\circ} \mathrm{C}$, relative humidity $60 \pm 10 \%$, PPFD of about $300-350 \mu \mathrm{mol} \mathrm{m}^{-2} \mathrm{~s}^{-1}$ ).

\section{Real-time Quantitative PCR}

Real-time PCR was carried out using RB SYBR master mix (RNA Biotechnology, Isfahan, Iran). The total RNA was isolated from fresh leaves using Iraizol reagent (RNA biotech, Iran). cDNA was synthesized using the RB M-MLV reverse transcriptase (RNA biotechnology, Co, Isfahan, Iran). The sequences of the real time primers designed to amplify $G S A$ were: GATTCCGTCAAAGGTGCTCG as forward and GTGGCAGCTTTAGGAACACC as Backward. The PCR conditions were $94{ }^{\circ} \mathrm{C}$ for 4 min followed by 40 cycles of $94{ }^{\circ} \mathrm{C}$ for $10 \mathrm{~s}, 62{ }^{\circ} \mathrm{C}$ for $40 \mathrm{~s}$, $72{ }^{\circ} \mathrm{C}$ for $60 \mathrm{~s}$, followed by $7 \mathrm{~min}$ at $72{ }^{\circ} \mathrm{C}$. Serial dilutions of cDNA were used to obtain optimized standard curve amplification efficiency and the best cDNA concentration for real-time 
PCR. PCR was performed in triplicate for each sample, and the expression levels were normalized to that of a tobacco actine gene.

To calculate total leaf area fifth copper leave for each plant were used in triplicate. Sum of second, third and fourth upper leave used as total dry weight. For measurements of water content, the fourth leaves were weighed. Next, the leaves were dried in an oven at $60{ }^{\circ} \mathrm{C}$ for $24 \mathrm{~h}$ and were weighed. WC was calculated as shown in this Equation.

$\mathrm{WC}=(\mathrm{FW}-\mathrm{DW}) / \mathrm{DW}$

\section{Photosynthetic pigments content}

Arnon (1967) method was used to measure chlorophyll contents (Arnon, 1967). $100 \mathrm{mg}$ of tobacco leaves were homogenized in $2 \mathrm{ml} \mathrm{80 \%} \mathrm{acetone.} \mathrm{Extracts} \mathrm{were} \mathrm{centrifuged} \mathrm{at} \mathrm{3,000} \mathrm{g}$ and the absorbance of supernatant was measured in triplicate. Absorbance was measured at wavelengths of 480,645 and $663 \mathrm{~nm}$ by ELISA reader (BioTek spectrophotometre Epoch). Chlorophyll content was calculated using the formula of Arnon and expressed in $\mathrm{mg} \mathrm{g}^{-1}$ fresh weight (FW). Carotenoid content was estimated using the formula of Kirk and Allen (1965) and Allen, 1965).

Chl a $=\left(\left(12.7 \times \mathrm{A}_{663}\right)-\left(2.69 \times \mathrm{A}_{645}\right) \times \mathrm{V}\right) / 100 \mathrm{~W}$

Chl b $=\left(\left(22.9 \times \mathrm{A}_{645}\right)-\left(4.68 \times \mathrm{A}_{663}\right) \times \mathrm{V}\right) / 100 \mathrm{~W}$

Total Chl $=\mathrm{Chl} \mathrm{a}+\mathrm{Chl} b$

$\operatorname{Car}=\left(\mathrm{A}_{480}+\left(\left(0.114 \times \mathrm{A}_{663}-\left(0.638 \times \mathrm{A}_{645}\right) \times \mathrm{V} \times 103\right) / 112.5 \times \mathrm{W}\right.\right.$

\section{ALA content}

was measured in tobacco plants as described by Mauzeral and Granick (1956) with some modification (Mauzerall and Cranick, 1956) by Khozaei et al (2010). $100 \mathrm{mg}$ of tobacco leaves were homogenized, in $1 \mathrm{ml}$ of Phosphate buffer $50 \mathrm{Mm}$ made by mixing $\mathrm{K}_{2} \mathrm{HPO}_{4}$ and $\mathrm{KH}_{2} \mathrm{PO}_{4}$, pH:6.8. Samples were centrifuged for $10 \mathrm{~min}$ at $16000 \mathrm{~g}$, and then $400 \mu \mathrm{l}$ of supernatant was mixed with $100 \mu \mathrm{l}$ of ethyl acetoacetate and boiled for $10 \mathrm{~min}$ at $100{ }^{\circ} \mathrm{C}$. After cooling the samples were spun again for $5 \mathrm{~min}$ at $16000 \mathrm{~g}$ and the supernatant was transferred to a new tube and mixed with $500 \mu \mathrm{l}$ of modified Ehrlich's reagent $(373 \mathrm{ml}$ acetic acid, $90 \mathrm{ml} 70 \%(\mathrm{v} / \mathrm{v})$ 
perchloric acid, $1.5 \mathrm{gr} \mathrm{HgCl}_{2}, 9.1 \mathrm{gr}$ 4-dimethlaminobenzaldehyde, built reagent to 1 lit adding $500 \mathrm{ml} \mathrm{H} \mathrm{H}_{2} \mathrm{O}$ ). Calorimetric Determination was measured at $553 \mathrm{~nm}$ and the ALA content of tobacco samples were calculated using a standard curve generated by commercial ALA. Absorption was measured in triplicate.

\section{Soluble and Insoluble Sugar Content}

Were extracted using the method described by Sheligl (1986). About $100 \mathrm{mg}$ of dried tobacco leaves were extracted in $15 \mathrm{ml}$ of hot $80 \%$ ethanol $\left(80{ }^{\circ} \mathrm{C}\right) .1 \mathrm{ml} 5 \%(\mathrm{w} / \mathrm{v})$ phenol and $5 \mathrm{ml}$ concentrated $\mathrm{H}_{2} \mathrm{SO}_{4}$ were added to $2 \mathrm{ml}$ plant extract and mixed thoroughly. The reaction mixture was allowed to stand for $30 \mathrm{~min}$ before the absorbance was recorded at 485 . Soluble sugars content of the sample was calculated based on calibration curve from a glucose standard. Starch content was extracted from the residual plant material from the soluble sugar extraction described above. Barium hydroxide and Zinc sulfate solvents used for separation of pigments and other components from the residual plant material (Sheligl, 1986). The insoluble products were assayed by the same phenol-sulfuric method described above.

\section{Photosynthesis Parameters Survey}

Gas exchange characteristics [Net photosynthesis $\left(\mathrm{A}_{\mathrm{n}}\right)$, and intercellular $\mathrm{CO}_{2}$ concentration $(\mathrm{Ci})$ ] were measured by portable photosynthesis system (CI-340 Handheld Photosynthesis SystemUSA) equipped with a $25 \mathrm{~mm} \times 25 \mathrm{~mm}$ square leaf chamber. Young expanded leaves (second, third and fourth leaf) were measured at light intensity about $300-350 \mu \mathrm{mol} \mathrm{m} \mathrm{m}^{-1}$ at air temperature about $25^{\circ} \mathrm{C}$ and atmosphere $\mathrm{CO}_{2}$ concentrations about $380 \mu 11^{-1}$.

\section{Statistical Analysis}

\section{RESULTS}

\section{Production of Transgenic Tobacco Overexpressing GSA} containing CaMV 35S promoter and NOS terminator (Fig. 2). 
The recombinant vector pBI121-GSA was transferred to Agrobacterium tumefaciens, and this was used to transform wild-type tobacco plant. Primary transform lines (T0) were selected on kanamycin-containing medium and subsequently moved to soil and grown to maturity, after confirmation of GSA gene in the primary resistance lines by PCR and specific primers, expression of the GSA mRNA in the kanamycin-resistant plants was confirmed by RT-PCR and concurrently, the quantification expression of GSA was carried out by real-time PCR among 17 individual transgenic lines (Fig. 3A).

Based on the gene activity screens in the T0 generation, three GSA overexpressing (GSAox) lines $(-1,-3$, and -4$)$ were selected for further analysis and propagated by self through to the T3 generation.

\section{Increased GSA Activity Causes Enhanced Growth Rate}

To determine if the observed changes in GSA activity levels affect the plants morphology and physiology, wild-type and GSA over expressing plants were grown in green house conditions and their growth parameters were compared (Fig. 3B). Appreciable differences in general plants growth were observed between transgenic plants and the wild-type control. Total leaf area, total leaf weight, fourth leaf dry weight, Internode third and fourth as well as plant height and specific leaf area were measured and the results showed significance increased in transform plants compared to the wild type (Tabel 1).

Increased GSA activity had positive effect on pigment synthesis and the carotenoid contents of transgenic plants.

The data clearly showed that parallel to increase GSA activity in transgenic plants the photosynthesis pigments were significantly altered. The level of Chlorophyll a and b were enhanced significantly from 15 to $110 \%$ of wild type plants (Fig. 4A, 4B). Also, total content of photosynthesis pigment (chlorophyll a and b) was increased 45 to $70 \%$ in transgenic lines (Fig. 4C). The ratio of chlorophyll a and b was reduced significantly 30 to $45 \%$ in transgenic plants compared to wild type (Fig. 4D). The amount of carotenoids was also measured from leaves of 
transgenic and the wild type plants. The results indicated a significant enhanced, 50-65\% in carotenoids contents of increased GSA lines compared to that from wild type (Fig. 4E).

Over Expression of GSA Activity Elevated Metabolites Include Soluble and Insoluble Sugars as Well as ALA Content in GSA Transgenic Lines.

To investigate whether increasing GSA activity may correlate with the level of soluble and insoluble sugars, plants materials were sampled from new expanded leaves of GSA transgenic lines and wild type plants. The data revealed that the content of soluble sugar was increased in GSA over expression lines 60 to $85 \%$ about to two fold higher levels than in wild type tobacco plants. The level of insoluble sugars also improved 40 to $115 \%$ in T0-1, T0-4 and also in T0-3 respectively compared to that found in the wild type (Fig. 5).

The data from the previous analysis suggested that chlorophyll and carotenoid contents were increased as GSA was expressed in GSA over-expressing lines. To test whether increased GSA activity alters the chlorophyll biosynthesis pathway in GSA over expression plants, the level of 5aminolevulinic acid (ALA) was determined. The samples from new expanded leaves of transgenic lines and wild type plant grown in green house conditions were extracted and examined for ALA quantification. As indicated in Fig. 6, the highest significant value for ALA was found in T0-1 (65\%), T0-4 (40\%) and T0-3 (25\%) lines respectively, compared to the equivalent wild type.

\section{Over Expression of GSA Activity Increased Photosynthesis Rate in Transgenic Lines}

In order to have a better understanding of increased GSA activity on the function of plant such as photosynthetic rate $\left(A_{n}\right)$, intercellular $\mathrm{CO}_{2}$ concentration $\left(\mathrm{C}_{\mathrm{i}}\right)$, plants were grown in greenhouse conditions and the young expanded leaves were subjected to photosynthesis analysis from both transgenic and wild type plants.

Photosynthetic rate was also affected by increasing level of GSA in transgenic tobacco plants. As GSA activity increased photosynthetic rate also increased in transgenic plants by 55 to $70 \%$ of equivalent wild type plants. High activity of GSA had also positive significant effect on 


\section{DISCUSSION}

We show here that overexpression of GSA increases the chlorophyll a and b, total chlorophyll and decreases the $\mathrm{Chl} \mathrm{a} / \mathrm{b}$ ratio in tobacco transgenic lines. Our data also showed that carotenoid content of GSA transgenic lines have increased $65 \%$ over that of wild type plant. In contrast, Höfgen (1994) claimed that down regulation of GSA activity in transgenic tobacco plants leads to severe plant damage and mimics in some tobacco transformants a wide variety of chlorophyll variegation patterns (Höfgen et al., 1994). Relative to wild type plant, chlorophyll content reduction was varied from $10 \%$ to $53 \%$ as GSA activity reduced ranging from $22 \%$ to $85 \%$ in GSA antisense plants. Further studies showed that up regulation in activity of chlorophyll biosynthesis enzymes may change the content of chlorophyll and pigments (Höfgen et al., 1994). Biswal et al. (2012) reported that over expression of chlorophyllide a oxygenase resulted in a high level of chlorophyll b but, $\mathrm{Chl} \mathrm{a} / \mathrm{b}$ ratio was decreased in tobacco or Arabidopsis CAOx plants were grown in both low or high light conditions (Tanaka et al., 2001; Biswal et al., 2012). Pattanayak et al. (2011) also reported that over expression protochlorophyllide oxidoreductase $C$ $(P O R C)$ had increased Chlorophyll content up to $28 \%$ over that of WT plants and had also a little higher carotenoid content (Pattanayak and Tripathy, 2011). In our study, simultaneous increased of ALA synthesis rate was observed in response to the elevation in activity of GSA enzyme in $G S A$ over expression tobacco plants. It is worth mentioning that increased in capacity of ALA synthesis was considered as a main factor to improve the pigment and chlorophyll content in transgenic lines. This was highly due to the function of ALA as a precursor to form the synthesis of chlorophylls, heme, and phycobilins in plants, algae, and many bacteria (Kannangara and Gough 1978; Sangwan and O’Brian 1993). The data obtained from ALA supplementation also suggests that exogenous ALA increased the content of chlorophylls, tetrapyrols and consequently promotes photosynthesis rate (Tanaka et al., 1993; Hotta et al., 1997; Xu et al., 2011; Ye et al., 2016; Tang et al., 2017; Liu et al., 2018).

In GSA over expression plants grown in greenhouse conditions, starch and soluble sugars content substantially increased to two fold as compared with that in wild-type plants throughout the diurnal cycle. Preliminarily analysis of GSA over expression lines using iodine staining also revealed (data not shown) that starch remained at the end of the day while no starch was 
detectable at the beginning of the day in both transgenic and wild type plants. These data provide evidence that synthesis or degradation of starch in transgenic plants over the day/night cycle was completely normal and accumulation of starch was most likely affected by increased activity of GSA rather than to extend any other reason in GSA over expression lines. These results showed that the additional starch produced in the GSA transgenic plants was being used in the dark period, possibly for plant growth and this was observed in increased of leaf area, dry weight and plant height.

Our data, along with those reported by Lefebvre et al. (2005), revealed a clear correlation between increased photosynthesis and starch accumulation (Lefebvre et al., 2005). Indeed, the total leaf weight of greenhouse-grown GSA plants increased by up to 10 to $17 \%$, as compared with wildtype plants. This finding is in agreement with data from a previous report in plants overexpressing. Sedoheptulose-bisphosphatase enzyme, where PSII photosynthetic efficiency, carbon assimilation, starch level, and dry matter accumulation consistently increased (Lefebvre $e t$ $a l .$, 2005). Along the same line, Transgenic tobacco plants over-expressing a chloroplast-targeted FBPase/SBPase bifunctional cyanobacterial enzyme also showed a $24 \%$ increase in final dry matter and a $50 \%$ increase in photosynthetic $\mathrm{CO}_{2}$ fixation (Miyagawa et al., 2001). It can be postulated that some of the enzyme involved in the Calvin cycle are in excess amount and reduction up to $40 \%$ in activity of this enzymes compared to wild type have no dramatic effect on photosynthesis capacity whereas, photosynthesis is very sensitive with a small reduction on activity of Transketolase and SBPase (Quick et al., 2004; Rosenthal et al., 2011; Khozeai et al., 2015). Small reduction in plastid transketolase activity (20\% to $40 \%$ ) reduced the supply of ribulose-1, 5-bisphosphate (important substrate to regenerate third phase of Calvin cycle) and resulted in an inhibition of photosynthesis (Henkes et al., 2001). Furthermore, Chlorophyll was unaltered in Transketolase antisense plants with $50 \%$ less in activity of transketolase compared to wild type. However, greater inhibition of TK expression led to localized loss of chlorophyll along the leaf. Total carotenoids also decreased when TK activity decreased to $50 \%$ of the wild-type value (Henkes et al., 2001). In contrast, over expression of transketolase in TK overexpressing tobacco plants changed the carbon flux with negative effect on thiamin biosynthesis pathway and extending a chlorotic phenotype accompanied with retardation in growth due to the shortage of 
cofactor thiamin pyrophosyhate for the TPP dependent enzymes (Khozeai et al., 2015). The same characters as photosynthesis, chlorophyll, carotenoids and growth rate were reported in antisense SBPase tobacco plant, reductions in SBPase activity resulted in a decline in the rate of carbon assimilation in the antisense plants, and this reduction was higher under saturating $\mathrm{CO}_{2}($ Harrison et al., 1998). The chlorophyll content of the leave of antisense SBPase plants was similar in wildtype except those plants with reduction of SBPase activity less than $20 \%$ of wild-type. This response resembles that seen in transformants with decrease expression of glutamate-1semialdehyde aminotransferase (Höfgen et al., 1994).

This was also confirmed that decreased TK and SBPase expression resulted a reduction in amount of shoot fresh weight, dry weight, leaf area and a marked decrease in shoot length and shoot biomass. The diurnal turnover of sucrose and starch in TK antisense showed a significant decreased in the content of carbohydrate levels such as sucrose, glucose and fructose in the leaves, whereas starch remained at high level (Harrison et al., 1998). Another interesting observation in our study was related to photosynthesis rate in GSA over expression lines. There was an additional increase (40-50\%) in net assimilation rate of GSA over expression lines compared to wild type plants. Our results are similar to those reported by Biswal et al. (2012) when the activity of chlorophyllide a oxygenas increased in CAO-overexpression tobacco and Arabidopsis plants and elevation of ALA, accumulation of chlorophyll content and increased in photosynthesis rate were evident. The previous finding data provide evidence that increased in photosynthesis rate in chlorophyllide a oxygenas overexpressed plants was mainly due to increase in chlorophyll b synthesis which was accompanied by an increased in lightharvesting chlorophyll proteins and light absorption level (Tanaka et al., 2001; Biswal et al., 2012). Our finding confirmed that any change in activity of enzymes in chlorophyll biosynthesis pathway caused the variation in content of chlorophylls and consequently altered the photosynthesis rate (Papenbrock et al., 2000; Tanaka et al., 2001; Shalygo et al., 2009). We hypothesis that photosynthesis is very sensitive to a small reduction/expression on activity of enzymes in chlorophyll biosynthesis pathway and this was mainly due to the mechanism of light absorbing and energy production occurred in this pathway. Altogether made the chlorophyll 
biosynthesis pathway as a great target for genetic modification leading to increase photosynthesis and for future improvement in crop productivity.

\section{ACKNOWLEDGMENTS}

We would like to express our thankful to RNA biotechnology Company for their vast input throughout this project.

\section{REFERENCES}

Alawady AE, Grimm B. 2005. Tobacco Mg protoporphyrin IX methyltransferase is involved in inverse activation of $\mathrm{Mg}$ porphyrin and protoheme synthesis. Plant Journal 41, 282-290.

An Y, Liu L, Chen L, Wang L. 2016a. ALA inhibits ABA-induced stomatal closure via reducing $\mathrm{H}_{2} \mathrm{O}_{2}$ and $\mathrm{Ca}^{2+}$ levels in guard cells. Frontiers in Plant Science 7.

An Y, Qi L, Wang L. 2016b. ALA pretreatment improves waterlogging tolerance of fig plants. Plos One 11.

Anjum SA, Li J, Lv J, Zong X, Wang L, Yang A, Yan R, Ali Z, Song J, Wang S. 2016. Regulation mechanism of exogenous ALA on growth and physiology of Leymus chinensis (Trin.) under salt stress. Chilean Journal of Agricultural Research 76, 314-320.

Arnon AN. 1967. Method of extraction of chlorophyll in the plants. Agronomy Journal 23, 112121.

Banerjee I, Mondal D, Martin J, Kane RS. 2010. Photoactivated antimicrobial activity of carbon nanotube - porphyrin conjugates. Langmuir 26, 17369-17374.

Beale SI. 1990. Biosynthesis of the tetrapyrrole pigment precursor, 5-aminolevulinic acid, from glutamate. Plant Physiology 93, 1273-1279.

Bindu RC, Vivekanandan M. 1998. Hormonal activities of 5-aminolevulinic acid in callus induction and micropropagation. Plant Growth Regulation 26, 15-18.

Biswal AK, Pattanayak GK, Pandey SS, Leelavathi S, Reddy VS, Tripathy G, Tripathy BC. 2012. Light intensity-dependent modulation of chlorophyll b biosynthesis and photosynthesis by overexpression of chlorophyllide a oxygenase in tobacco. Plant Physiology 159, 433-449.

Choi HP, Lee YM, Yun CW, Sung HC. 2008. Extracellular 5-aminolevulinic acid production by 
Escherichia coli containing the Rhodopseudomonas palustris KUGB306 hemA gene. Journal of Microbiology and Biotechnology 18, 1136-1140.

Ferradini N, Nicolia A, Capomaccio S, Veronesi F, Rosellini D. 2011. A point mutation in the Medicago sativa GSA gene provides a novel, efficient, selectable marker for plant genetic engineering. Journal of Biotechnology 156, 147-152.

Fuli Xu, Wang W, Yu D. 2012. Effect of 5-aminolevulinic acid on yield and quality of lettuce in sunlit greenhouse. African Journal of Biotechnology 11, 11591-11594.

Green MR, Sambrook J. 2012. Molecular cloning: A laboratory manual. New York: Cold Spring Harbor.

Han R, Gao G, Li Z, Dong Z, Guo Z. 2014. Effects of exogenous 5-aminolevulinic acid on seed germination of alfalfa (Medicago varia Martyn.) under drought stress. Japanese Society of Grassland Science, 1-8.

Harrison EP, Willingham NM, Lloyd JC, Raines CA. 1998. Reduced sedoheptulose-1,7bisphosphatase levels in transgenic tobacco lead to decreased photosynthetic capacity and altered carbohydrate accumulation. Planta 204, 27-36.

Henkes S, Sonnewald U, Badur R, Flachmann R, Stitt M. 2001. A Small Decrease of Plastid Transketolase Activity in Antisense Tobacco Transformants Has Dramatic Effects on Photosynthesis and Phenylpropanoid Metabolism. The Plant Cell 13, 535-551.

Hoagland DR, Arnon DI. 1950. The water-culture method for growing plants without soil. California Agricultural Experiment Station Publications 347, 1-32.

Höfgen R, Axelsen KB, Kannangara CG, Schüttke I, Pohlenz H-D, Willmitzer L, Grimm B, Wettstein D Von. 1994. A visible marker for antisense mRNA expression in plants: inhibition of chlorophyll synthesis with a glutamate-1-semialdehyde aminotransferase antisense gene. Proceedings of the National Academy of Sciences of the United States of America 91, 1726-1730. Horsch RB, Fry JE, Hoffmann NL, Eichholtz D, Rogers SG, Fraley RT. 1985. A simple and general method for transferring genes into plants. Science 227, 1229-1231.

Hotta Y, Tanaka T, Takaoka H, Takeuchi Y, Konnai M. 1997. New Physiological Effects of 5-Aminolevulinic Acid in Plants: The Increase of Photosynthesis, Chlorophyll Content, and Plant Growth. Bioscience, Biotechnology, and Biochemistry 61, 2025-2028. 
Iida K, Mimura I, Kajiwara M. 2002. Evaluation of two biosynthetic pathways to $\delta$ aminolevulinic acid in Euglena gracilis. European Journal of Biochemistry 269, 291-297.

Jung S, Back K, Yang K, Kuk YI, Chon SU. 2008. Defence response produced during photodynamic damage in transgenic rice overexpressing 5-aminolevulinic acid synthase. Photosynthetica 46, 3-9.

Jung S, Yang K, Lee DE, Back K. 2004. Expression of Bradyrhizobium japonicum 5aminolevulinic acid synthase induces severe photodynamic damage in transgenic rice. Plant Science 167, 789-795.

Kang Z, Ding W, Gong X, Liu Q, Du G, Chen J. 2017. Recent advances in production of 5aminolevulinic acid using biological strategies. World Journal of Microbiology and Biotechnology 33, 200.

Kannangara CG, Gough SP. 1978. Biosynthesis of 5-aminolevulinate In greening barley leaves: Glutamate 1-semialdehyde aminotransferase. Carlsberg Research Communications 43, 185-194.

Khozeai M, Fisk S, Lawson T, Gibon Y, Sulpice R, Stitt M, Lefebvre SC, Raines CA. 2015. Overexpression of plastid transketolase in tobacco results in a thiamine auxotrophic phenotype. The Plant Cell Online, 1-17.

Kirk JTO, Allen RL. 1965. Dependence of chloroplast pigment synthesis on protein synthesis: Effect of actidione. Biochemical and Biophysical Research Communications 21, 523-530.

Kuk YI. 2007. Growth, yield and grein quality in transgenic Rice overexpressing 5aminolevuulinic acid synthase. The Korean Society of Weed Science 27, 257-267.

Lefebvre S, Lawson T, Zakhleniuk O V, Lloyd JC, Raines CA. 2005. Increased Sedoheptulose-1 , 7-Bisphosphatase Activity in Transgenic Tobacco Plants Stimulates Photosynthesis and Growth from an Early Stage in Development. Plant Physiology 138, 451-460. Liu X, Zhu L, Song Q, Chang J, Ye J, Zhang W, Liao Y, Xu F. 2018. Effects of 5aminolevulinic acid on the photosynthesis, antioxidant system, and $\alpha$-bisabolol content of Matricaria recutita. Notulae Botanicae Horti Agrobotanici Cluj-Napoca 46, 418-425.

Maruyama-Nakashita A, Hirai MY, Funada S, Fueki S. 2010. Exogenous application of 5aminolevulinic acid increases the transcript levels of sulfur transport and assimilatory genes, sulfate uptake, and cysteine and glutathione contents in Arabidopsis thaliana. Soil Science and 
Plant Nutrition 56, 281-288.

Mauzerall D, Cranick S. 1956. The occurrence and determination of $\delta$-minolevulinic acid and porphobilinogen in urine. Journal of Biological Chemistry 219, 435-446.

McCormac AC, Fischer A, Kumar AM, Söll D, Terry MJ. 2001. Regulation of HEMA1 expression by phytochrome and a plastid signal during de-etiolation in Arabidopsis thaliana. The Plant Journal 25, 549-561.

Miyagawa Y, Tamoi M, Shigeoka S. 2001. Overexpression of a cyanobacterial fructose-1,6/sedoheptulose-1, 7-bisphosphatase in tobacco enhances photosynthesis and growth. Nature Biotechnology 19, 965-969.

Mochizuki N, Tanaka R, Grimm B, Masuda T, Moulin M, Smith AG, Tanaka A, Terry MJ. 2010. The cell biology of tetrapyrroles: a life and death struggle. Trends in Plant Science 15, 488498.

Murasnige T, Skoog F. 1962. A revised medium for rapid growth and bio assays with Tobacco tissue cultures. 15, 473-497.

Nishihara E, Kondo K, Parvez MM, Takahashi K, Watanabe K, Tanaka K. 2003. Role of 5aminolevulinic acid (ALA) on active oxygen-scavenging system in NaCl-treated spinach (Spinacia oleracea). Journal of Plant Physiology 160, 1085-1091.

Papenbrock J, Pfundel E, Mock H-P, Grimm B. 2000. Decreased and increased expression of the subunit CHL I diminishes $\mathrm{Mg}$ chelatase activity and reduces chlorophyll synthesis in transgenic tobacco plants. The Plant Journal 22, 155-164.

Pattanayak GK, Tripathy BC. 2011. Overexpression of protochlorophyllide oxidoreductase $C$ regulates oxidative stress in arabidopsis (JM Schnur, Ed.). Plos One 6, e26532.

Perez MH, Shintani TT, Rodriguez BL, Davis J, Harrigan RC. 2013. The role of 5aminolevulinic acid (5-ALA) and sleep. International Journal of Clinical Medicine 04, 1-7.

Phour M, Ghai A, Rose G, Dhull N, Singh Sindhu S. 2018. Role of Aminolevulinic Acid in Stress Adaptation and Crop Productivity. International Journal of Current Microbiology and Applied Sciences 7, 1516-1524.

Quick WP, Fichtner K, Schulze E-D, Wendler R, Leegood RC, Mooney H, Rodermel SR, Bogorad L, Stitt M. 2004. Decreased ribulose-1,5-bisphosphate carboxylase-oxygenase in 
transgenic tobacco transformed with 'antisense' rbcS. Planta 188, 522-531.

Rebeiz AC, Juvik JA, Rebeiz AC. 1988a. Porphyric. Pesticide biochemistry and physiology. 30, $11-27$.

Rebeiz AC, Juvik JA, Rebeiz Carole C. 1988b. Porphyric insecticides 1. Concept and phenomenology. Pesticide Biochemistry and Physiology 30, 11-27.

Rosenthal DM, Locke AM, Khozaei M, Raines CA, Long SP, Ort DR. 2011. Over-expressing the C3 photosynthesis cycle enzyme Sedoheptulose-1-7 Bisphosphatase improves photosynthetic carbon gain and yield under fully open air $\mathrm{CO}_{2}$ fumigation (FACE). BMC Plant Biology 11, 123.

Sangwan I, O'Brian MR. 1993. Expression of the soybean (Glycine max) glutamate 1Semialdehyde aminotransferase gene in symbiotic root nodules. Plant Physiology 102, 829-834.

Sasaki K, Watanabe M, Tanaka T, Tanaka T. 2002. Biosynthesis, biotechnological production and applications of 5-aminolevulinic acid. Applied Microbiology and Biotechnology 58, 23-29.

Shalygo N, Czarnecki O, Peter E, Grimm B. 2009. Expression of chlorophyll synthase is also involved in feedback-control of chlorophyll biosynthesis. Plant Molecular Biology 71, 425-436.

Sheligl HQ. 1986. Die verwertung orgngischer souren durch Chlorella lincht. Planta Journal, 4751.

Sun YP, Zhang ZP, Wang LJ. 2009. Promotion of 5-aminolevulinic acid treatment on leaf photosynthesis is related with increase of antioxidant enzyme activity in watermelon seedlings grown under shade condition. Photosynthetica 47, 347-354.

Tanaka R, Koshino Y, Sawa S, Ishiguro S, Okada K, Tanaka A. 2001. Overexpression of chlorophyllide a oxygenase (CAO) enlarges the antenna size of photosystem II in Arabidopsis thaliana. The Plant Journal 26, 365-373.

Tanaka Y, Tanaka A, Tsuji H. 1993. Effects of 5-Aminolevulinic Acid on the Accumulation of Chlorophyll-b and Apoproteins of the Light- Harvesting Chlorophyll a/b Protein Complex of Photosystem-II. Plant and Cell Physiology 34, 465-472.

Tang X-Q, Wang Y, Lv T-T, Xiao Y-H. 2017. Role of 5-aminolevulinic acid on growth, photosynthetic parameters and antioxidant enzyme activity in NaCl-stressed Isatis indigotica Fort. Russian Journal of Plant Physiology 64, 198-206.

Wachowska M, Muchowicz A, Firczuk M, Gabrysiak M, Winiarska M, Wańczyk M, 
Bojarczuk K, Golab J. 2011. Aminolevulinic acid (ALA) as a prodrug in photodynamic therapy of cancer. Molecules 16, 4140-4164.

Wang LJ, Jiang WB, Huang BJ. 2004. Promotion of 5-aminolevulinic acid on photosynthesis of melon (Cucumis melo) seedlings under low light and chilling stress conditions. Physiologia Plantarum 121, 258-264.

Wang LJ, Sun YP, Zhang ZP, Kang L. 2010. Effects of 5-aminolevulinic acid (ALA) on photosynthesis and chlorophyll fluorescence of watermelon seedlings grown under low light and low temperature conditions. Acta Horticulturae 856, 159-166.

Wei ZY, Zhang ZP, Lee MR, Sun YP, Wang LJ. 2012. Effect of 5-aminolevulinic acid on leaf senescence and nitrogen metabolism of pakchoi under different nitrate levels. Journal of Plant Nutrition 35, 49-63.

Wettstein D Von, Gough S, Kannangara CG. 1995. Chlorophyll biosynthesis. The Plant Cell 7, 1039-1057.

Wu Y, Jin X, Liao W, Hu L, Dawuda MM, Zhao X, Tang Z, Gong T, Yu J. 2018. 5Aminolevulinic acid (ALA) alleviated salinity stress in cucumber seedlings by enhancing chlorophyll synthesis pathway. Frontiers in Plant Science 9, 1-16.

Xie L, Hall D, Eiteman MA, Altman E. 2003. Optimization of recombinant aminolevulinate synthase production in Escherichia coli using factorial design. Applied Microbiology and Biotechnology 63, 267-273.

Xu F, Cheng S, Zhu J, Zhang W, Wang Y. 2011. Effects of 5-aminolevulinic acid on chlorophyll, photosynthesis, soluble sugar and flavonoids of Ginkgo biloba. Notulae Botanicae Horti Agrobotanici Cluj-Napoca 39, 41-47.

Xu L, Zhang W, Ali B, Islam F, Zhu J, Zhou W. 2015. Synergism of herbicide toxicity by 5aminolevulinic acid is related to physiological and ultra-structural disorders in crickweed (Malachium aquaticum L.). Pesticide Biochemistry and Physiology 125, 53-61.

Yang Z, Chang Z, Sun L, Yu J, Huang B. 2014. Physiological and metabolic effects of 5aminolevulinic acid for mitigating salinity stress in creeping bentgrass (W Zhou, Ed.). Plos One 9, e116283.

Yang P, Liu W, Cheng X, Wang J, Wang Q, Qi Q. 2016. A new strategy for production of 5- 
aminolevulinic acid in recombinant Corynebacterium glutamicum with high yield (S-J Liu, Ed.). Applied and Environmental Microbiology 82, 2709-2717.

Yang M, Yin K, Guo Y, MA E, Zhang J. 2011. A photosensitivity insecticide, 5-aminolevulinic acid, exerts effective toxicity to Oxya chinensis (Orthoptera: Acridoidea). Agricultural Sciences in China 10, 1056-1063.

Ye J, Chen Q, Tao T, Wang G, Xu F. 2016. Promotive effects of 5-Aminolevulinic acid on growth, photosynthetic gas exchange, chlorophyll, and antioxidative enzymes under salinity stress in Prunnus persica (L.) Batseh Seedling. Emirates Journal of Food and Agriculture 28, 786.

Yu X, Jin H, Liu W, Wang Q, Qi Q. 2015. Engineering Corynebacterium glutamicum to produce 5-aminolevulinic acid from glucose. Microbial Cell Factories 14, 183.

Zavgorodnyaya A, Papenbrock J, Grimm B. 1997. Yeast 5-aminolevulinate synthase provides additional chlorophyll precursor in transgenic tobacco. The Plant Journal 12, 169-178.

Zhang ZP, Yao QH, Wang LJ. 2010. Expression of yeast Heml gene controlled by Arabidopsis HemAl promoter improves salt tolerance in Arabidopsis plants. BMB reports 43, 330-336.

Zhang Z-P, Yao Q-H, Wang L-J. 2011. Expression of yeast Heml controlled by Arabidopsis HemAl promoter enhances leaf photosynthesis in transgenic tobacco. Molecular Biology Reports 38, 4369-4379.

Zhang B, Ye BC. 2018. Pathway engineering in Corynebacterium glutamicum S9114 for 5aminolevulinic acid production. 3 Biotech 8, 247. 
Table 1. Effect of increased GSA on growth parameter of transgenic lines and the wild type plants.

\begin{tabular}{|c|c|c|c|c|c|c|}
\hline $\begin{array}{l}\text { Growth } \\
\text { Parameter }\end{array}$ & $\begin{array}{c}\text { Total Leaf Area } \\
\left(\mathrm{cm}^{2}\right)\end{array}$ & $\begin{array}{l}\text { Total Leaf } \\
\text { Weight (gr) }\end{array}$ & $\begin{array}{l}\text { Fourth Leaf Dry } \\
\text { Weight (gr) }\end{array}$ & $\begin{array}{l}\text { Internode Third } \\
\text { And Fourth (cm) }\end{array}$ & $\begin{array}{ll}\text { Plant Height } \\
(\mathrm{cm})\end{array}$ & $\begin{array}{l}\text { Specific Leaf Area } \\
(\mathrm{SLA})\left(\mathrm{m}^{2} \cdot \mathrm{g}^{-1}\right)\end{array}$ \\
\hline T0-1 & $591.27 \pm 27.33^{\mathrm{a}}$ & $8.98 \pm 0.517^{a}$ & $0.24 \pm 0.01^{a}$ & $0.92 \pm 0.076^{a}$ & $9.5 \pm 0.5^{\mathrm{a}}$ & $741.56 \pm 30.75^{a}$ \\
\hline T0-3 & $573.76 \pm 20.84^{a}$ & $8.9 \pm 0.46^{\mathrm{a}}$ & $0.223 \pm 0.015^{\mathrm{a}}$ & $0.68 \pm 0.076^{b}$ & $8.4 \pm 1.15^{\mathrm{a}}$ & $659.06 \pm 20.16^{b c}$ \\
\hline T0-4 & $565.35 \pm 24.04^{\mathrm{a}}$ & $8.47 \pm 0.56^{a b}$ & $0.22 \pm 0.01^{b}$ & $0.6 \pm 0.1^{b c}$ & $6.73 \pm 0.97^{b}$ & $700.23 \pm 25.36^{\mathrm{ab}}$ \\
\hline Wild Type & $487.87 \pm 17.7^{b}$ & $7.7 \pm 0.3^{b}$ & $0.2 \pm 0.01^{b}$ & $0.45 \pm 0.05^{\mathrm{c}}$ & $6.43 \pm 0.51^{b}$ & $601.63 \pm 32.23^{\mathrm{c}}$ \\
\hline
\end{tabular}

The values are the mean of five different measurements $(\mathrm{n}=5)$. Different letters in the same column represent significant differences at the $95 \%$ confidence level. 
Fig. 1 In animals ALA is synthesized from combination of succinyl-CoA and glycine catalyzed by ALA-S, but in Plants ALA is synthesized from Glu that respectively convert by Glu-RS, Glu-TR, and GSA to ALA. Two molecules of ALA form PBG then four molecules of PBG are condensed to form Urogen III. Proto IX is synthesis by several modifications in Urogen III. $\mathrm{Fe}^{+2}$ and $\mathrm{Mg}^{2+}$ insert by Ferroclatase and MgChelatase into Proto IX. The pathway is branched into the synthesis of Heme and phytochrome or Chl a and Chl b at this step. (Dashed arrows indicated several reaction is down and filed arrows indicated one reaction is down).

Fig. 2 Structure of T-DNA region of binary vector pBI121-GSA constructed for expression of GSA; a cassette composed of a full-length Medicago sative cDNA under the control of the cauliflower mosaic virus 35S promoter, NOS terminator (NOS-ter) and a kanamycin resistance gene (NPTII) as a selection marker.

Fig. 3 (A) Relative Expression of seventeen line of transforms tobacco. (B) Leaf area of transforms tobacco and wild-type plants are compared. Tobacco plants were grown in a controlled-environment cabinet (temperature $25 \pm 5{ }^{\circ} \mathrm{C}$, relative humidity $60 \pm 10 \%$, PPFD of about $300-350 \mu \mathrm{mol} \mathrm{m}^{-2} \mathrm{~s}^{-1}$ ).

Fig. 4 Photosynthesis pigments content of transform lines T0-1, T0-3, T0-4 compared to WT tobacco. (a) chlorophyll total (b) chlorophyll a (c) chlorophyll b (d) Chlorophyll a / Chlorophyll b (e) Carotenoids. Means \pm SD followed by the same letter(s) in each row are not significantly different, as measured by Duncan's test $(\mathrm{P} \leq 0.05)$. Each data is the average of measurements of 4 plants. Measurements from individual extracts were made in triplicate.

Fig. 5 The soluble sugar and insoluble sugar content of fresh leaf of transform lines T0-1, T0-3, T0-4 compared to WT tobacco. Means \pm SD followed by the same letter(s) in each row are not significantly different, as measured by Duncan's test $(\mathrm{P} \leq 0.05)$. Each data is the average of measurements of 4 plants. Measurements from individual extracts were made in triplicate.

Fig. 6 ALA content of fresh leaf of transform lines T0-1, T0-3, T0-4 compared to WT tobacco. Means \pm SD followed by the same letter(s) in each row are not significantly different, as measured by Duncan's test $(\mathrm{P} \leq 0.05)$. Each data is the average of measurements of 4 plants. Measurements from individual extracts were made in triplicate.

Fig. 7 Comparison of leaf photosynthesis parameters between wild type and transgenic. (A) Intercellular $\mathrm{CO}_{2}$ concentration; (B) $\mathrm{Net}^{\mathrm{CO}} \mathrm{O}_{2}$ Assimilation rate. Means \pm SD followed by the same letter(s) in each row are not significantly different, as measured by Duncan's test ( $\mathrm{P} \leq$ 0.05). Each data is the average of measurements of 4 plants. 
bioRxiv preprint doi: https://doi.org/10.1101/640425; this version posted May 17, 2019. The copyright holder for this preprint (which was not certified by peer review) is the author/funder. All rights reserved. No reuse allowed without permission. 


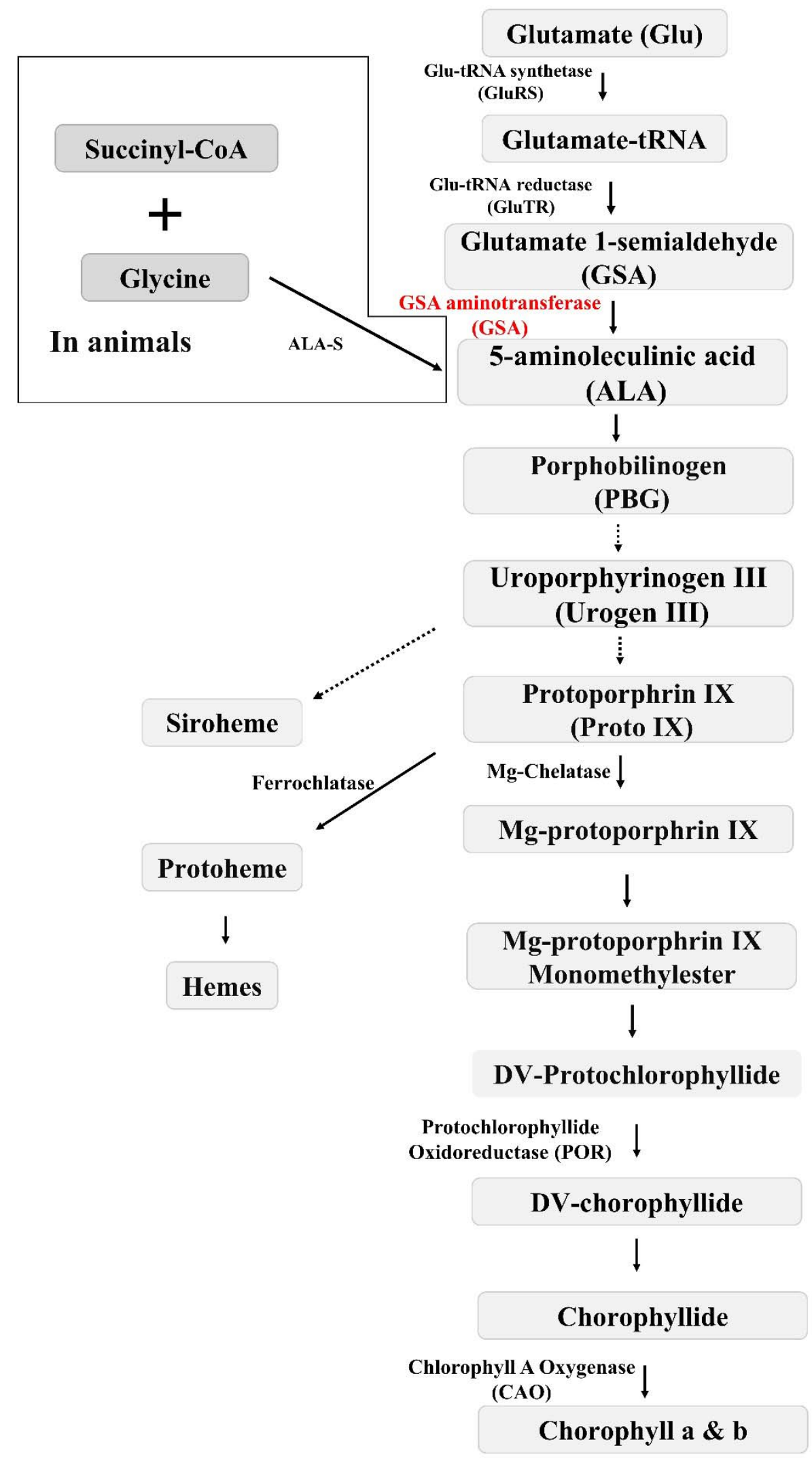


bioRxiv preprint doi: https://doi.org/10.1101/640425; this version posted May 17, 2019. The copyright holder for this preprint (which was not certified by peer review) is the author/funder. All rights reserved. No reuse allowed without permission.

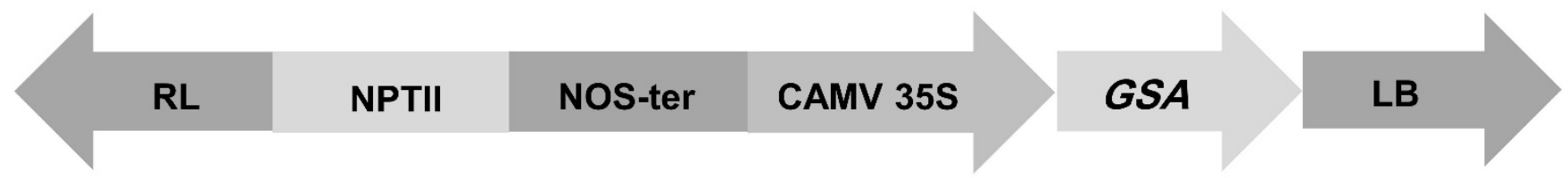



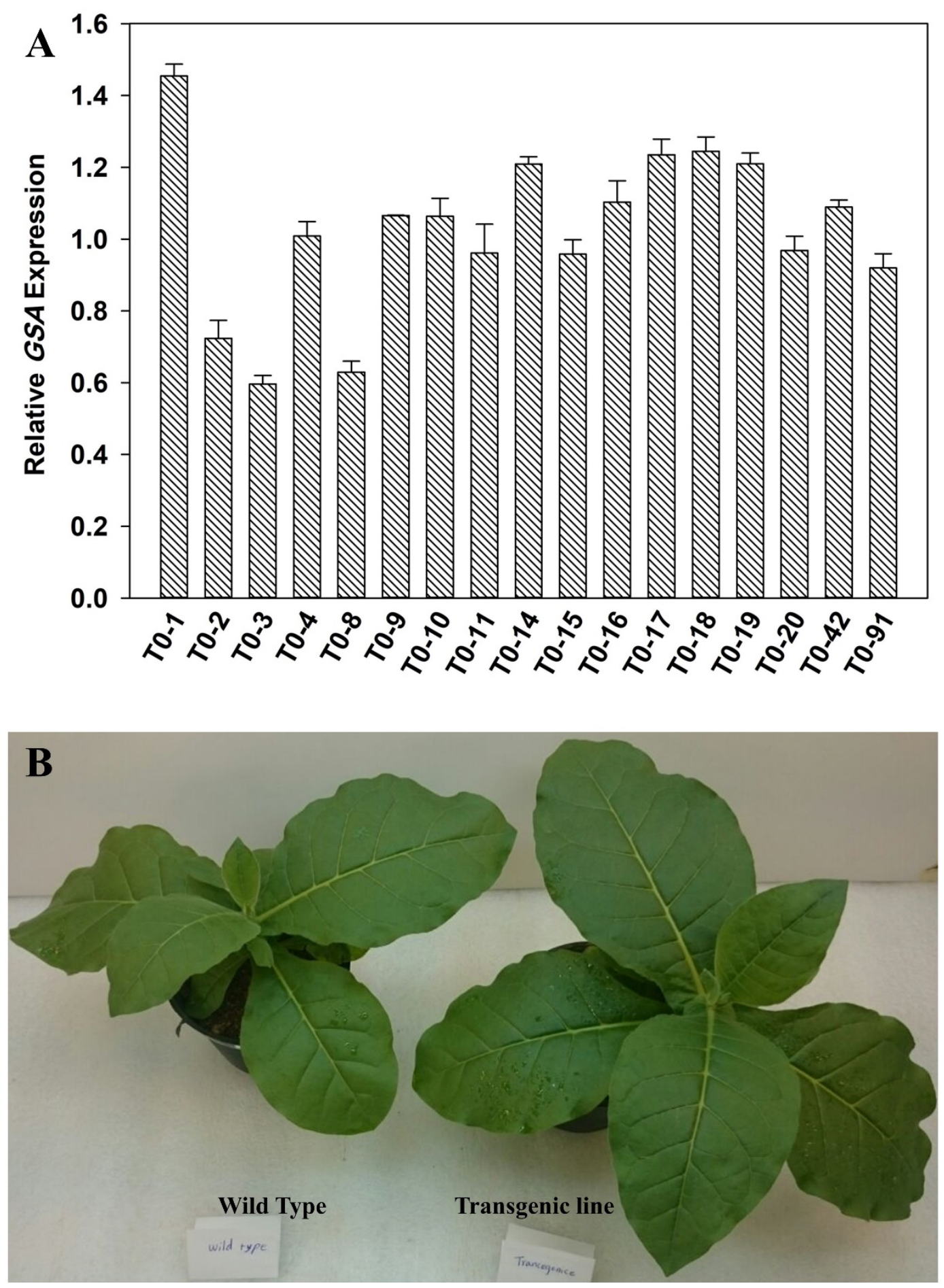
bioRxiv preprint doi: https://doi.org/10.1101/640425; this version posted May 17, 2019. The copyright holder for this preprint (which was not certified by peer review) is the author/funder. All rights reserved. No reuse allowed without permission.
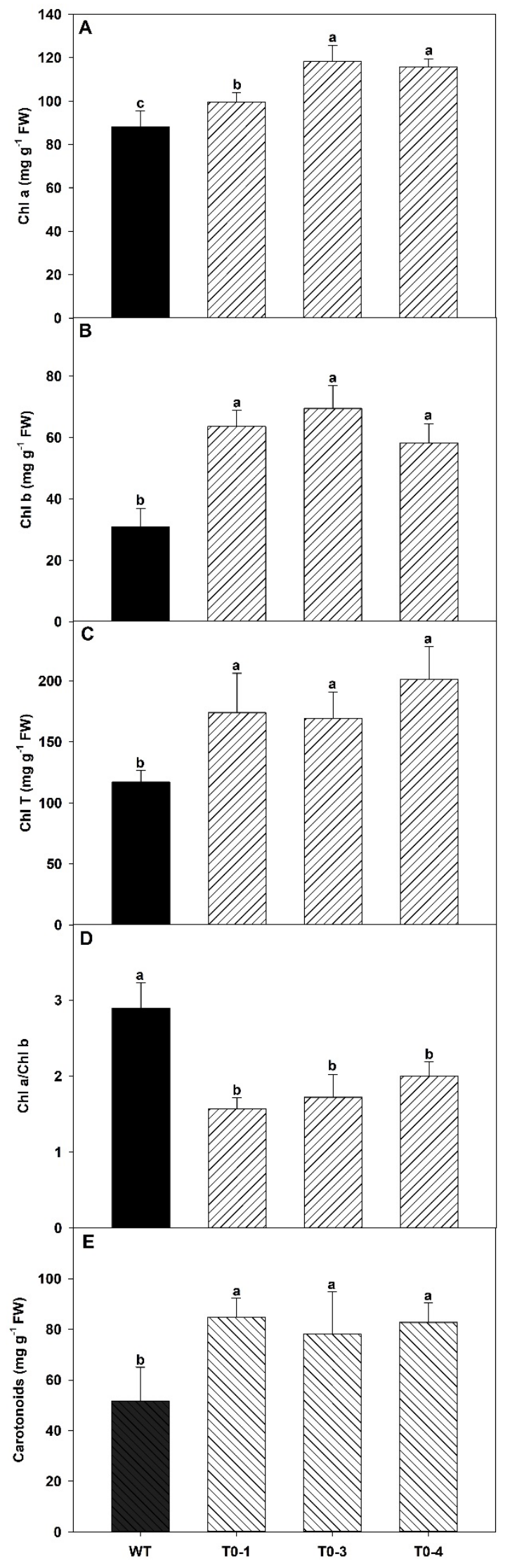


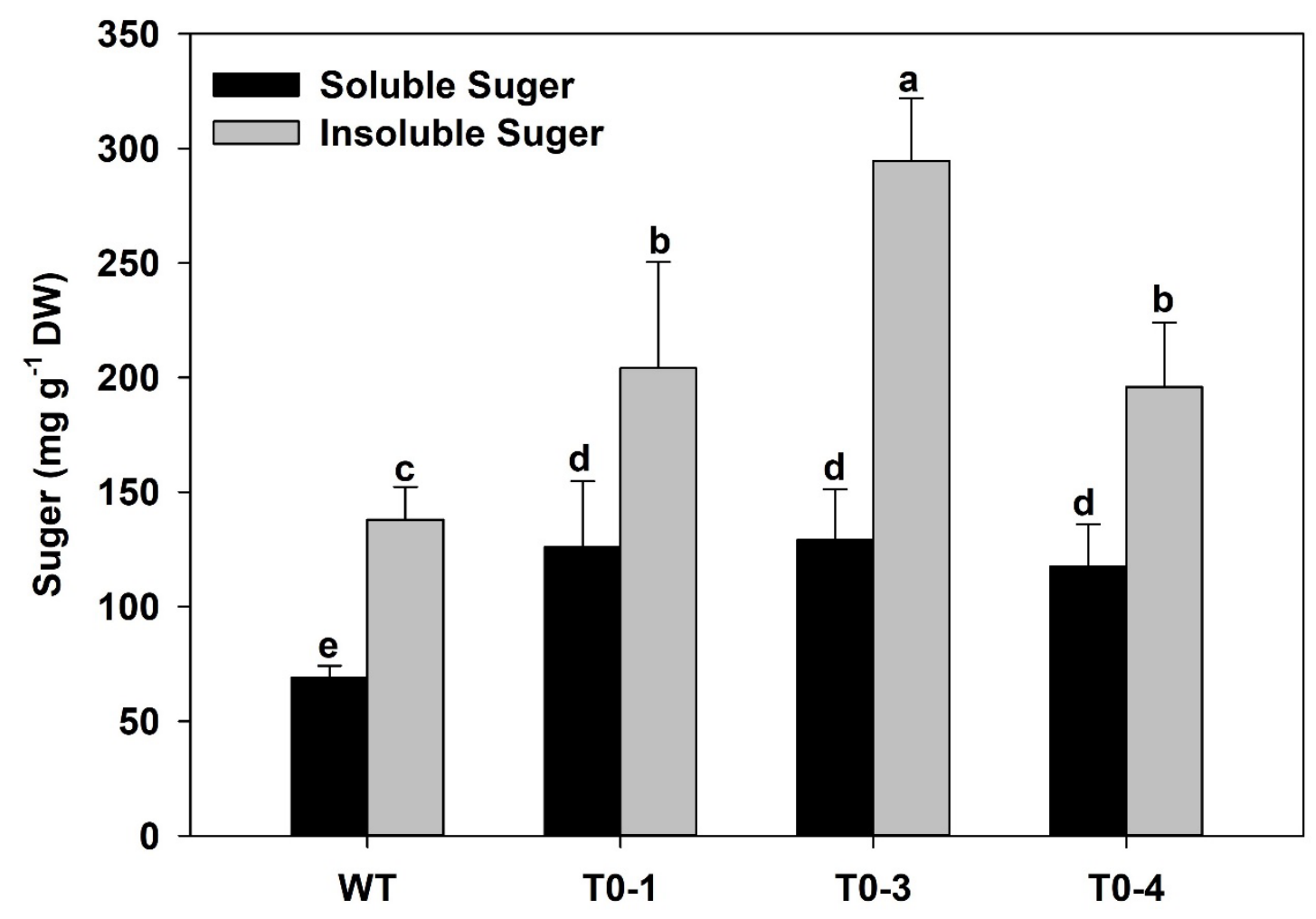


bioRxiv preprint doi: https://doi.org/10.1101/640425; this version posted May 17, 2019. The copyright holder for this preprint (which was not certified by peer review) is the author/funder. All rights reserved. No reuse allowed without permission.

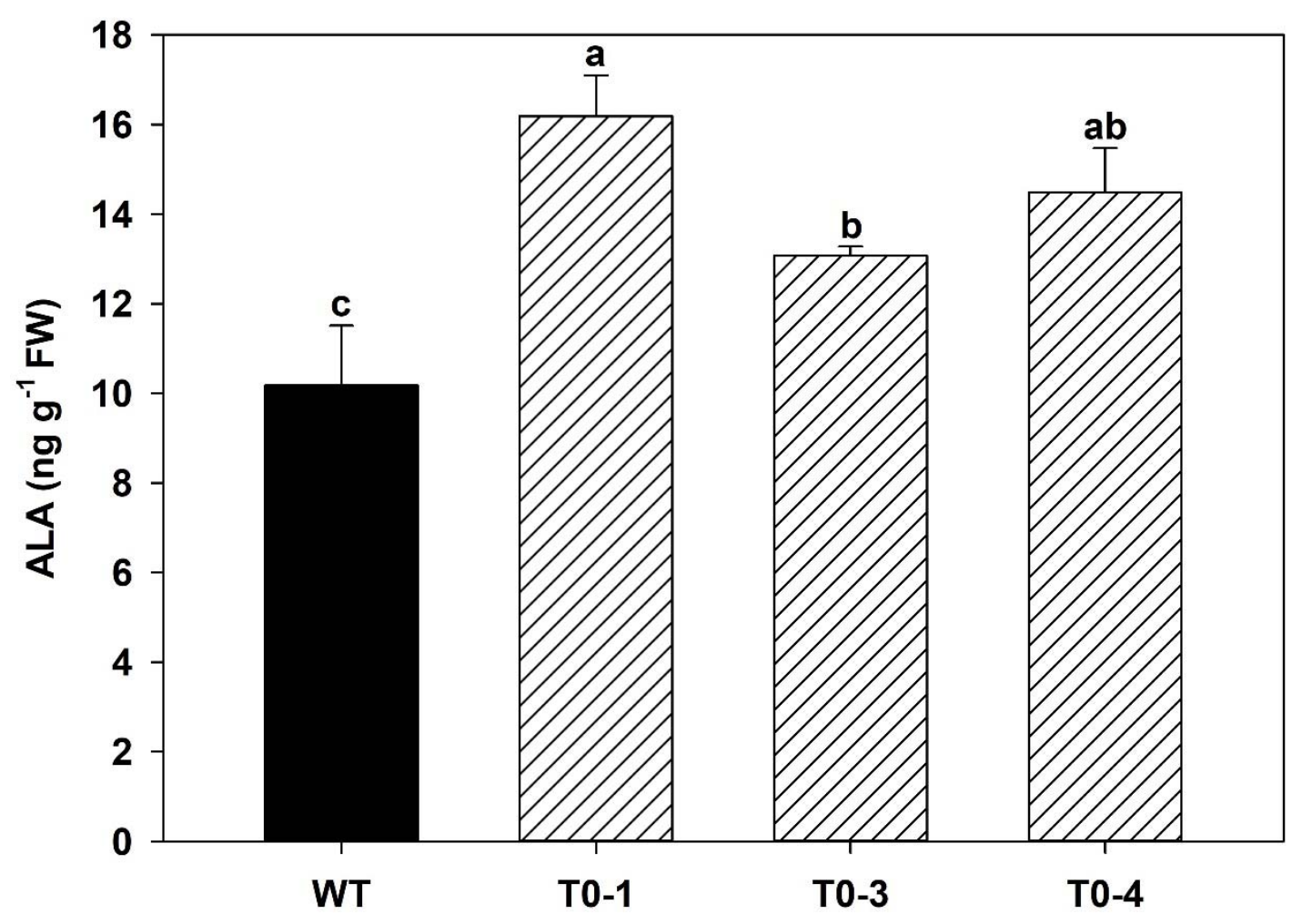




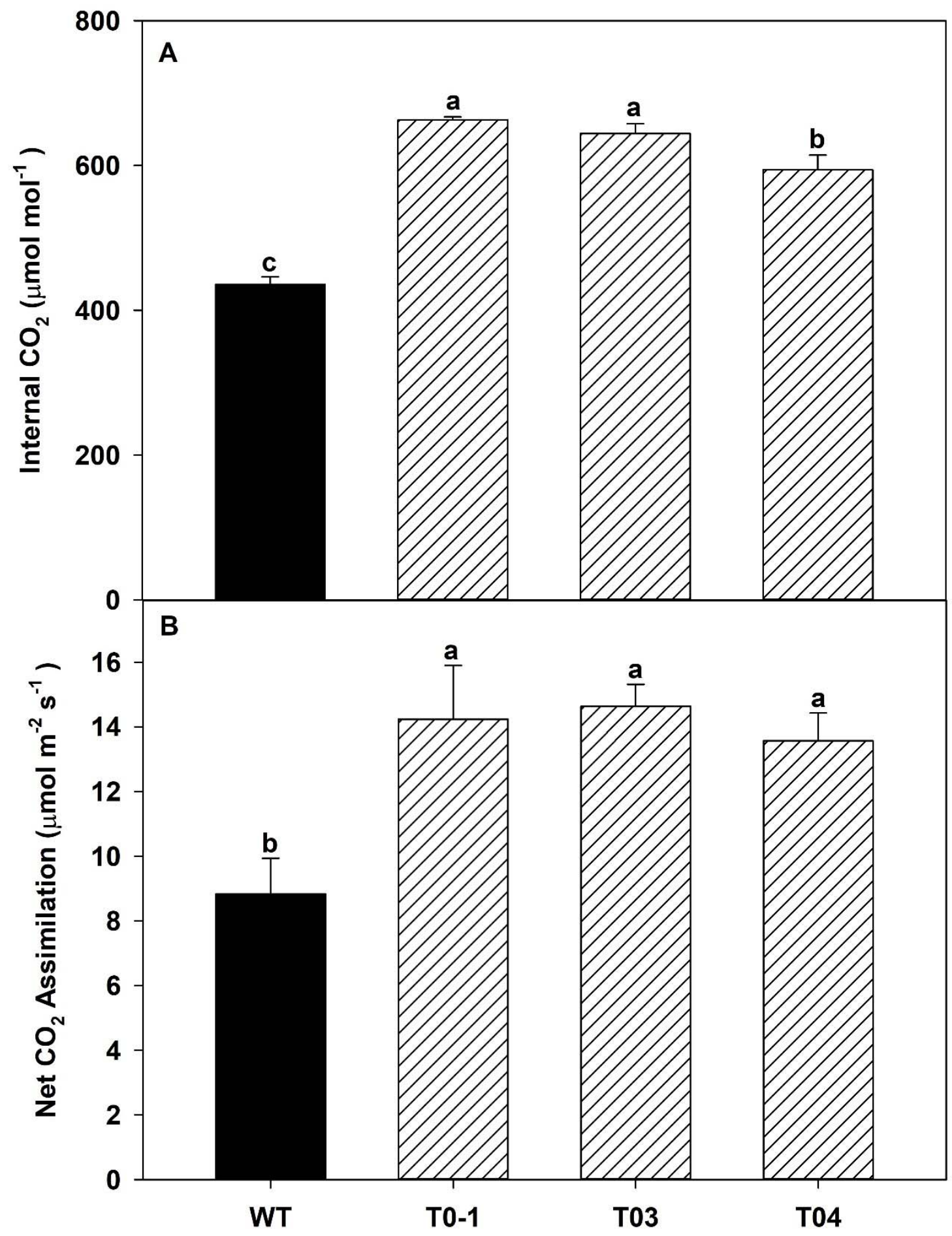


bioRxiv preprint doi: https://doi.org/10.1101/640425; this version posted May 17, 2019. The copyright holder for this preprint (which was not certified by peer review) is the author/funder. All rights reserved. No reuse allowed without permission.

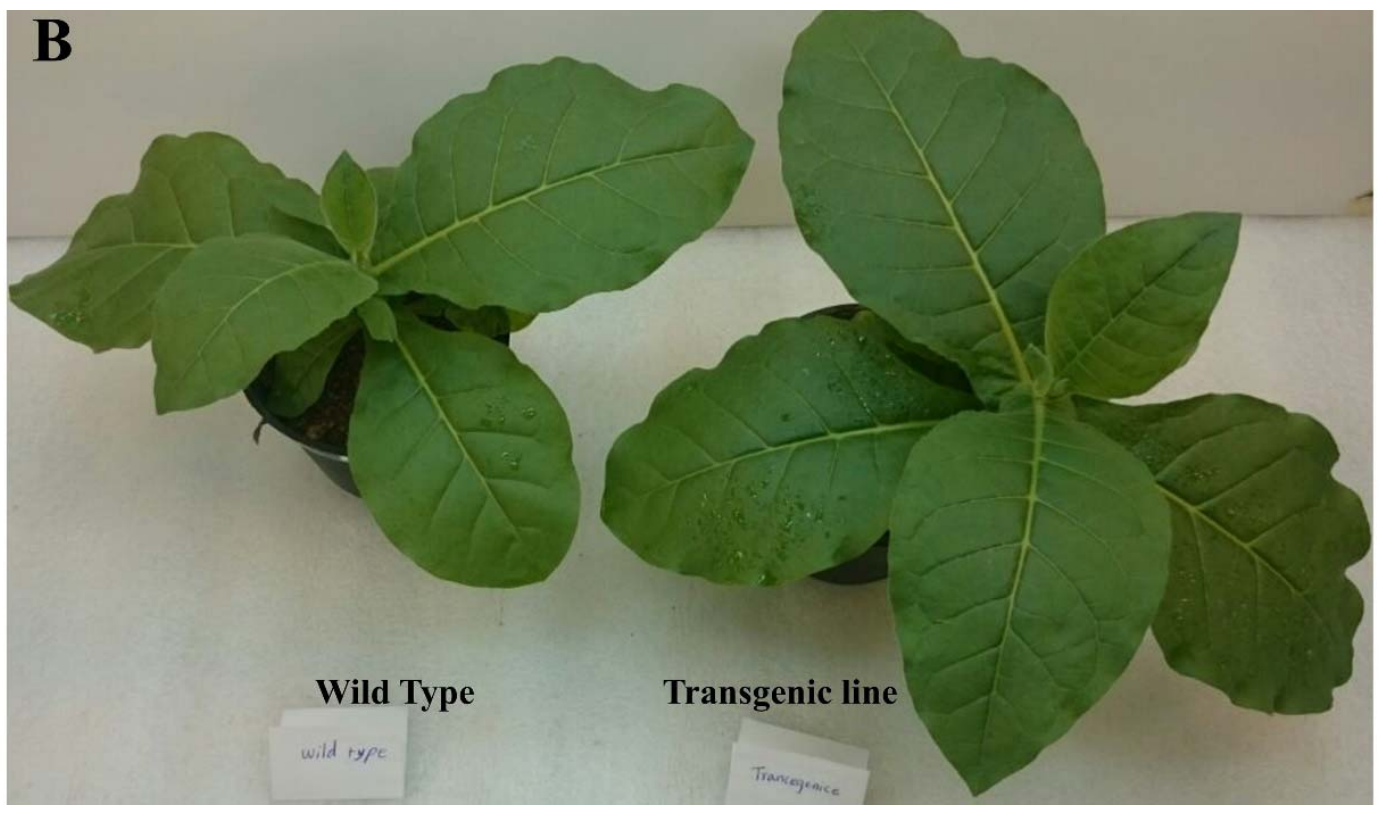

